\title{
Low-flow left ventricle percutaneous venting during peripheral veno-arterial extracorporeal membrane oxygenation for the management of transient left ventricle distension
}

\author{
Jason E Bloom ${ }^{1 *}$, Vincent Pellegrino ${ }^{1}$, David C McGiffin ${ }^{1}$, Angeline Leet ${ }^{1}$, Peter J Bergin ${ }^{1}$, David M Kaye ${ }^{1,2,3}$ and Dion Stub $^{1,2,3}$ \\ ${ }^{1}$ Department of Cardiovascular Medicine, The Alfred Hospital, Melbourne, Australia \\ ${ }^{2}$ School of Public Health and Preventive Medicine, Monash University, Melbourne, Australia \\ ${ }^{3}$ Baker IDI Heart and Diabetes Institute, Melbourne, Australia
}

\begin{abstract}
Left ventricle $(\mathrm{LV})$ distension and resultant pulmonary oedema is a common complication arising from veno-arterial extracorporeal membrane oxygenation (VAECMO) circulatory support. We report a case of a 45-year-old male receiving VA-ECMO following an anterior ST-Elevation myocardial infarct, who developed refractory pulmonary oedema due to transient LV distension. His LV was successfully decompressed via a minimally invasive, percutaneously inserted 7-French pigtail aspiration catheter into the ventricle's cavity.
\end{abstract}

\section{Learning objectives}

Left ventricular (LV) distension and pulmonary oedema are common complications associated with Veno-Arterial Extracorporeal Membrane Oxygenation (VA-ECMO) support. From this case, we demonstrate a successful percutaneous technique to decompress the LV with a retrogradely placed pigtail catheter into the LV cavity, which aspirates blood into the ECMO venous return line.

\section{Introduction}

Extracorporeal membrane oxygenation (ECMO) is an increasingly utilised circulatory support strategy for the management of life threatening respiratory or cardiac failure $[1,2]$. In the case of cardiogenic shock, the ECMO circuit is typically configured in a venoarterial (VA) fashion via cannulation of peripheral blood vesselsfor example the femoral artery and vein. However, in the setting of significant left ventricular (LV) systolic dysfunction, especially a noncontractile ventricle, and with any degree of aortic incompetence, the LV may be pressure loaded and rendered incapable of adequately ejecting the preload against the afterload generated by the retrograde arterial ECMO flow. Therefore, inadequate LV unloading may occur that results in LV distension and subsequent left atrial hypertension and pulmonary oedema [3].

The development of pulmonary oedema due to LV distension in patients being supported with VA-ECMO represents a significant management challenge, with a reported incidence ranging between 10 $60 \%$ [4]. We present case of a percutaneous technique to decompress the LV by inserting a pigtail catheter retrogradely across the aortic valve into the left ventricular cavity that drains directly into the ECMO venous return line.

\section{Case}

A 45-year-old male was transferred to our institution following a delayed presentation anterior ST-Elevation myocardial infarct. Prior to this event, he had no significant medical history. Following successful percutaneous coronary intervention to the proximal left anterior descending artery, the patient developed refractory cardiogenic shock, despite the use of an intra-aortic balloon pump and escalating inotropic support. Accordingly, he was percutaneously cannulated, under ultrasound guidance for VA-ECMO (Maquet Rotaflow pump), with insertion of a right femoral vein (23Fr) cannula, right internal jugular vein (17Fr) cannula and left femoral artery $(21 \mathrm{Fr})$ cannula, left femoral artery backflow cannula, and transferred for ongoing management.

Initial transthoracic echocardiogram (TTE) was performed, with ECMO flow at $5.2 \mathrm{~L} / \mathrm{min}, 3,260 \mathrm{RPM}$, and the patient supported with Adrenaline $0.05 \mathrm{mcg} / \mathrm{Kg} / \mathrm{min}$, Noradrenaline $0.1875 \mathrm{mcg} / \mathrm{Kg} / \mathrm{min}$ and Milrinone $0.25 \mathrm{mcg} / \mathrm{Kg} / \mathrm{min}$. TTE demonstrated severe left ventricular systolic dysfunction (LVEF 20\%), with preserved RV function. The inter-atrial septum was bowed towards the right atrium, suggestive of raised left atrial filling pressures. Valve function was satisfactory with only trivial aortic regurgitation and the aortic valve opened with each cardiac cycle.

${ }^{\star}$ Correspondence to: Jason E Bloom, Department of Cardiovascular Medicine, The Alfred Hospital, Commercial Road, Melbourne, VIC 3004, Australia, Tel: +61-390-762-000; Fax: +61-390-762-461; E-mail: Jason.elliott.bloom@gmail.com

Key words: extracorporeal membrane oxygenation, ECMO, ischaemic cardiomyopathy, pulmonary oedema, left ventricle distension

Received: April 29, 2019; Accepted: May 08, 2019; Published: May 13, 2019 
Baseline pulmonary congestion progressed to overt pulmonary oedema by day 4 of VA-ECMO support. Routine measures to treat the pulmonary oedema were unsuccessful. These included, optimisation of inotropic support, mean arterial pressure (MAP) control, furosemidedriven diuresis, continuous veno-venous haemodiafiltration (with significant negative fluid balance), positive end-expiratory pressure (PEEP) and ECMO flow optimisation. Despite these measures the pulmonary oedema significantly progressed, and an alternative method of LV decompression was deemed necessary. Under ultrasound, fluoroscopic and transoesopahgeal echocardiographic guidance, having excluded an LV thrombus, a 7-Fr PRO-FLO Medtronic Vascular pigtail catheter was placed across the aortic valve into the ventricular cavity in the cardiac catheterisation laboratory (Figure 1). Left ventricular end diastolic pressure was $16 \mathrm{mmHg}$ at the time of procedure. The catheter was then attached to the ECMO venous return line, aspirating $90 \mathrm{ml} /$ min as determined by ultrasound velocity time index.

Within 24 hours of the procedure, there was a near complete radiographic resolution of the pulmonary oedema (Figure 2). These findings occurred in the absence of significant changes to ECMO flow, inotrope or haemofiltration parameters. Of note, MAP targets were reduced from 70-80 to $60-70 \mathrm{mmHg}$ during this period, suggesting that afterload reduction in addition to LV decompression contributed to the patient's clinical improvement. After 4 days, considering the improved pulmonary oedema, the LV catheter was removed, and the patient was successfully extubated.

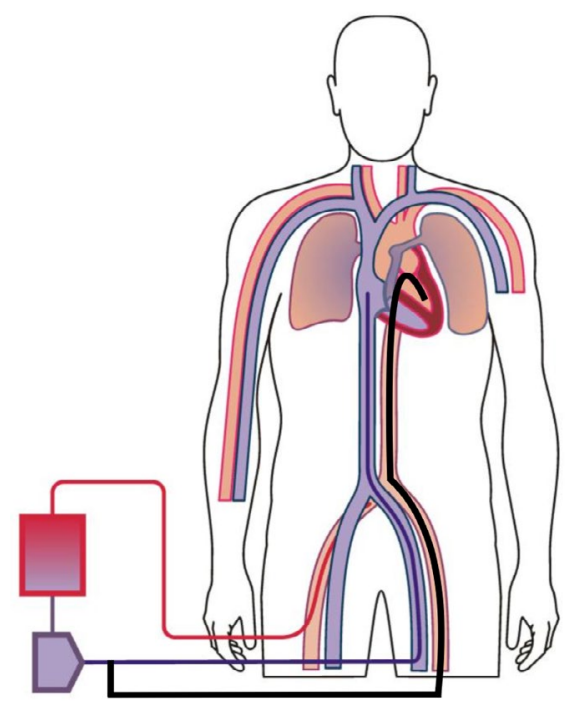

Figure 1. Percutaneous trans-aortic pigtail aspiration catheter (Black) delivering blood from the left ventricle into the venous (purple) return venous ECMO return

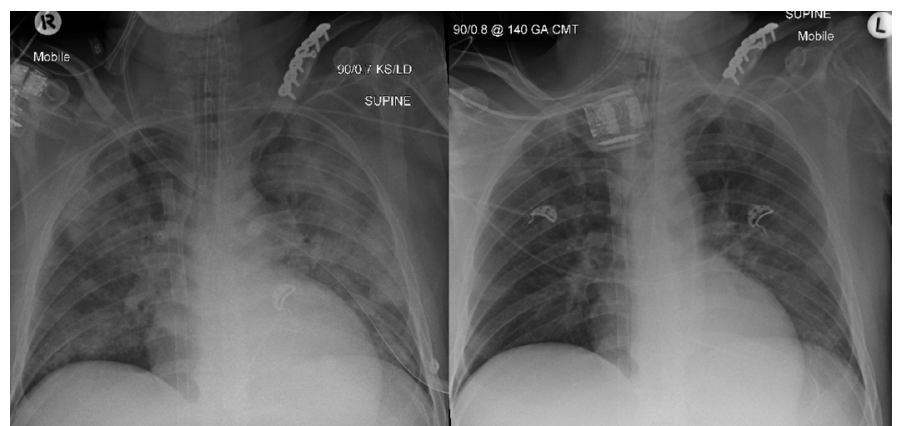

Figure 2. Left image: Day 0, pre-LV pigtail insertion demonstrating significant pulmonary oedema. Right image: Day 1, post LV pigtail insertion showing a marked improvement in pulmonary oedema
Due to the significant ischaemic cardiomyopathy, the patient was unable to be weaned from ECMO support. On day 48, following a period of rehabilitation (physical therapy in bed) and recovery of renal function, a left ventricular assist device was implanted (Heart Ware, Medtronic) as a bridge to orthotopic heart transplantation. The patient was discharged home 92 days after admission.

\section{Discussion}

Left ventricular distension and refractory pulmonary oedema are an increasingly recognised management challenge in patients on VAECMO. In this patient cohort, the requirement for invasive LV/LA decompression has been estimated to range from 12-68\% [2]. In animal models, the utilisation of high flow VA-ECMO has been demonstrated to impair LV systolic function and result in LV distension $[5,6]$. However, with adequate LV venting, these adverse haemodynamic complications can be attenuated [6]. Thus, effective LV venting may improve ventricular function and recovery, reduce pulmonary oedema and the need for ongoing respiratory support [6].

At our institution, LV distension and pulmonary oedema in a VA-ECMO supported patient is typically managed with non-invasive measures in the first instance. In the case presented, where unequal ventricular function occurs, with some preservation of LV systolic function, progression of LV distension was gradual. The primary medical interventions in this situation can include fluid balance optimisation, the use of high PEEP to reduce afterload and decreases RV pre-load, reduced inotropic support, control of MAP and a reduction of ECMO flow where possible. However, when these therapies are inadequate, invasive management strategies may be required. Various approaches have been utilised including intra-aortic balloon pumps to reduce afterload and percutaneous blade or balloon atrial septostomy to create a left-to-right shunt $[3,7,8]$. Recently, Pappalardo et al. [9] retrospectively examined the concomitant use of VA-ECMO and a percutaneous transaortic axial flow pump (Impella: Abiomed Inc, USA) and, after propensity matching, demonstrated a mortality benefit with the concurrent use of this device. As a last resort, other more invasive options can directly vent the LA or LV vented via a sternotomy or thoracotomy. We elected to utilise the strategy described because the patient had a competent aortic valve that was opening with each cardiac cycle and the left ventricular end diastolic pressure was only moderately elevated. These factors suggested that low-flow decompression would likely be able to assist with the management of the pulmonary oedema [3]. Impella was not considered as it is not readily available at our institution.

We propose that the use of a trans-aortic pigtail catheter represents a minimally invasive, safe, inexpensive and effective method of LV decompression in patients with transient forms of LV distention on VA-ECMO. However, unlike a similar report published by Hong et al. [10], we believe that the use of a larger 7Fr aspiration catheter (compared with 5Fr) affords the ability to more adequately and rapidly decompress the left ventricle if required.

\section{References}

1. Alfred Health. Alfred Health Extracorporeal Membrane Oxygenation (ECMO) Guideline. Alfred Health Intensive Care Unit. 2017. Available from: http://www. alfredicu.org.au/assets/Documents/ICU-Guidelines/ECMO/ECMOGuideline.pdf

2. Tramm R, Ilic D, Davies AR, Pellegrino VA, Romero L, et al. (2015) Extracorporea membrane oxygenation for critically ill adults. Cochrane Database of Syst Rev 1: CD010381. [Crossref]

3. Soleimani B, Pae WE (2012) Management of left ventricular distension during peripheral extracorporeal membrane oxygenation for cardiogenic shock. Perfusion 27 326-31. [Crossref] 
Bloom JE (2019) Low-flow left ventricle percutaneous venting during peripheral veno-arterial extracorporeal membrane oxygenation for the management of transient left ventricle distension

4. Rupprecht L, Florchinger B, Schopka S, Schmid C, Philipp A, et al. (2013) Cardiac Decompression on Extracorporeal Life Support: A Review and Discussion of The Literature. ASAIO J 59: 547-53. [Crossref]

5. Ostadal P, Mlcek M, Kruger A, Hala P, Lacko S, et al. (2015) Increasing Venoarterial Extracorporeal Membrane Oxygenation Flow Negatively Affects Left Ventricular Performance in a Porcine Model of Cardiogenic Shock. J Transl Med 13: 266. [Crossref]

6. Kurihara H, Kitamura M, Shibuya M, Tsuda Y, Endo M, et al. (1997) Effect of Transaortic Catheter Venting on Left Ventricular Function During Venoarterial Bypass. ASAIO J 43: 838-41. [Crossref]

7. Madershahian N, Salehi-Gilani S, Naraghi H, Stoeger E, Wahlers T (2011) Biventricular Decompression by Trans-Septal Positioning of Venous ECMO Cannula Through Patent Foramen Ovale. J Cardiovasc Surg 52: 900. [Crossref]
8. Swartz MF, Smith F, Byrum CJ, Alfieris GM (2012) Transseptal Catheter Decompression of the Left Ventricle During Extracorporeal Membrane Oxygenation. Pediatr Cardiol 33: 185-187. [Crossref]

9. Pappalardo F, Schulte C, Pieri M, Schrage B, Contri R, et al. (2017) Concomitan implantation of Impella ${ }^{\circledR}$ on top of veno-arterial extracorporeal membrane oxygenation may improve survival of patients with cardiogenic shock. Eur J Heart Failure 19: 404412. [Crossref]

10. Hong TH, Byun JH, Yoo BH, Hwang SW, Kim HY, et al. (2015) Successful Left-Heart Decompression During Extracorporeal Membrane Oxygenation in an Adult Patient by Percutaneous Transaortic Catheter Venting. Korean J Thorac Cardiovasc Surg 48: 210 213. [Crossref]

Copyright: (C2019 Bloom JE. This is an open-access article distributed under the terms of the Creative Commons Attribution License, which permits unrestricted use, distribution, and reproduction in any medium, provided the original author and source are credited. 